\title{
Flower morphometry of members of the genus Dactylorhiza Necker ex Nevski (Orchidaceae) from the Altai Mountains of Kazakhstan
}

\author{
AIDAR A. SUMBEMBAYEV ${ }^{1,2, \boldsymbol{v}}$, SAULE I. ABUGALIEVA ${ }^{3}$, ALEVTINA N. DANILOVA ${ }^{1}$, \\ EKATERINA V. MATVEYEVA ${ }^{1}$, DARIUSZ L. SZLACHETKO ${ }^{4}$ \\ ${ }^{1}$ Altai Botanical Garden. Ridder, 071300, Kazakhstan. ^email: aydars@list.ru \\ 2al-Farabi Kazakh National University. Almaty, 050040, Kazakhstan \\ ${ }^{3}$ Institute of Plant Biology and Biotechnology. Almaty, 050040, Kazakhstan \\ ${ }^{4}$ University of Gdansk. Gdansk, 80-308, Poland
}

Manuscript received: 24 June 2021. Revision accepted: 29 July 2021.

\begin{abstract}
Sumbembayev AA, Abugalieva SI, Danilova AN, Matveyeva EV, Szlachetko DL. 2021. Flower morphometry of members of the genus Dactylorhiza Necker ex Nevski (Orchidaceae) from the Altai mountains of Kazakhstan. Biodiversitas 22: 3545-3555. Several species of Dactylorhiza (Orchidaceae) from the Altai mountains of Kazakhstan have been investigated regarding their morphological flower variability. Significant metric characters were identified allowing to differentiate between the four species: $D$. incarnata, $D$. fuchsii, D. maculata and D. salina. The morphometric structure of flowers was analyzed by comparing 17 metric parameters in representatives of 11 populations. We identified the most variable and stable traits as well as distinctive features for each species. A high degree of flower morphometric diversity was revealed from principal component analysis for species and populations. Cluster analysis demonstrated the structure of the population diversity. Structural schemes have been compiled from data of the photographic processing of flower morphometry, the analysis of variance ANOVA, and the degree of variation at the population level. Useful characters are provided for further taxonomic work on members of the genus Dactylorhiza in Kazakhstan.
\end{abstract}

Keywords: flower scheme, metric characters, population diversity, species identification

\section{INTRODUCTION}

The genus Dactylorhiza Necker ex Nevski (Orchidaceae) consists of about 75 species (Averyanov 1990a, Ståhlberg and Hedrén 2008) - most species recorded from northwestern Europe and southern Siberia (Delforge 2001; Efimov 2016). The Flora of Kazakhstan (1958) lists eight species of Dactylorhiza; the EuroSiberian D. fuchsii (Druce) Soo ranks as endangered in the Red Data Book of Kazakhstan (2014). The study area encompasses four species from the nominal section of Dactylorhiza, i.e. D. incarnata (L.) Soo and D. salina (Turcz. ex Lindl.) Soo from the subsection Dactylorhiza, as well as D. fuchsii (Druce) Soo and D. maculata (L.) Soo from the subsection Maculatae (Parl.) Aver. - all of which being classified as of "Least concern" by the IUCN (2020).

Dactylorhiza is a taxonomically complex genus (Delforge 2001; Hedren 2001a, 2001b; Bateman 2003; Pillon et al. 2006; Shipunov and Efimov 2015; Brandrud et al. 2020). Its representatives are marked by a high phenotypic variability, which often complicates attempts of drawing borderlines between species even within the same or close plant communities (Naczk 2018; Averyanov 1990). These issues have been addressed variously on the basis of morphology (van Straaten 1988; Shipunov et al. 2005a), micromorphology (Hedrén 2009; Gamarra et al. 2015; Akbulut 2016) morphometry (Tyteca 1999; Pedersen 2002; Shipunov 2005b; Bateman 2006; Ashish 2012; Shirokov 2020), anatomy (Aybeke et al. 2010), molecular biology (Bateman et al. 2003; Shipunov et al. 2004; Devos et al. 2006; Pillon et al. 2007; Inda et al. 2010; Balao 2017), and molecular genetics (Givnish 2015; Efimov 2016; Bateman 2018a, 2018b; Kakia 2020).

The Kazakhstan part of the Altai Mountain country (Kazakhstan Altai) is the largest fragment of the SayanAltai Mountain system, representing its southwestern outskirts located within Kazakhstan (kazgeo.ucoz.org). The climatic conditions of the Kazakhstan Altai are determined its location in the center of the Eurasian continent with an equal distance from the oceans in each direction (Baytulin 2011). For this region, a recent survey lists all members of the orchid family along with distribution data, including the genus Dactylorhiza (Sumbembayev et al. 2020).

There are relatively few studies using morphometry to estimate population variability and those are mainly concentrated on terrestrial orchids from temperate regions (Bateman and Denholm 1988; Bateman and Farrington 1989; Dufrêne et al. 1991). Taxa of the genus Dactylorhiza have largely been distinguished on the basis of features of flower lip and spur (Renz 1984; Bateman 2018, Akbulut 2020). Many problematic issues on Dactylorhiza remain in regard to their taxonomy and regional occurrence (Vakhrameeva 2014).

The main goal of this research has been to study the morphological variability of the flowers of the members of Dactylorhiza from the Altai mountains of Kazakhstan using metric characters, allowing to divide their populations into morphological groups along representative and reliable diagnostic features. 


\section{MATERIALS AND METHODS}

Field expeditions to the Altai mountains of Kazakhstan were carried out in 2019 and 2020, during which 11 populations of four species were studied: $D$. incarnata (L.) Soo, $D$. fuchsii (Druce) Soo, D. maculata (L.) Soo, and $D$. salina (Turcz. ex Lindl.) Soo classified according to Averyanov (1990a) in the nominal section of Dactylorhiza. The species were determined according to Averyanov (1988, 1989, 1990b). The locations of the studied populations of Dactylorhiza Necker ex Nevski are presented in Figure 1. The plant material collected included inflorescences of live plants; 20 samples from each population (Table 1).

To characterize the ecological requirements of species, descriptions of the stages of ecological factors were used (Landolt 1977). The levels of ecological scales (insolation, humidity, soil acidity, soil nutrient richness) were determined in specific natural habitats (Table 1). For a qualitative characteristic, only fully formed, developed inflorescences in the phase of mass flowering were selected. Inflorescences were stored in alcohol $(96 \%)$ /glycerin/water $(4: 2: 1)$. For measurements, one flower was taken from the central part of each inflorescence. The measurements were carried out using a Micros MC300 microscope (Austria). Morphometric characters are used according to Kirilova (2018). To characterize the morphometry of the flower shape, 17 metric parameters were studied (Figure 2).

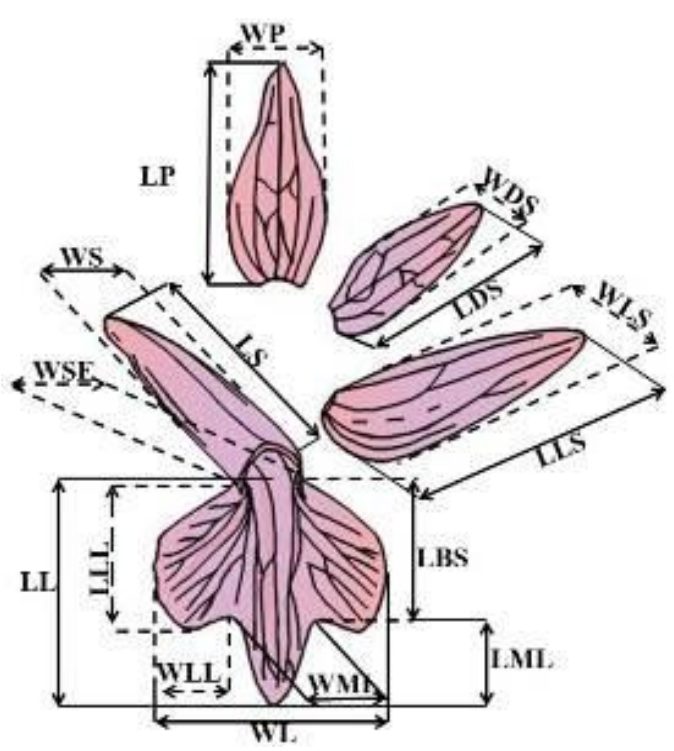

Figure 2. Flower morphometric features. Legend: LL: Length of labellum, mm; WL: Width of labellum, mm; WSE: Width of spur entrance, mm; LDS: Length of dorsal sepal, mm; WDS: Width of dorsal sepal, mm; LLS: Length of lateral sepals, mm; WLS: Width of lateral sepals, mm; LS: Length of spur, mm; WS: Width of spur (in the middle), mm; LLL: Length of lateral lobe of labellum, mm; WLL: Width of lateral lobe of labellum, mm; LBS: Length from the base of spur entrance to base of sinus, mm; LO: Length of ovary, mm; [LML=LL-LBS]: Length of labellum middle lobe, mm; WML: Width of labellum middle lobe, $\mathrm{mm}$; LP: Length of petals, mm; WP: Width of petals, $\mathrm{mm}$

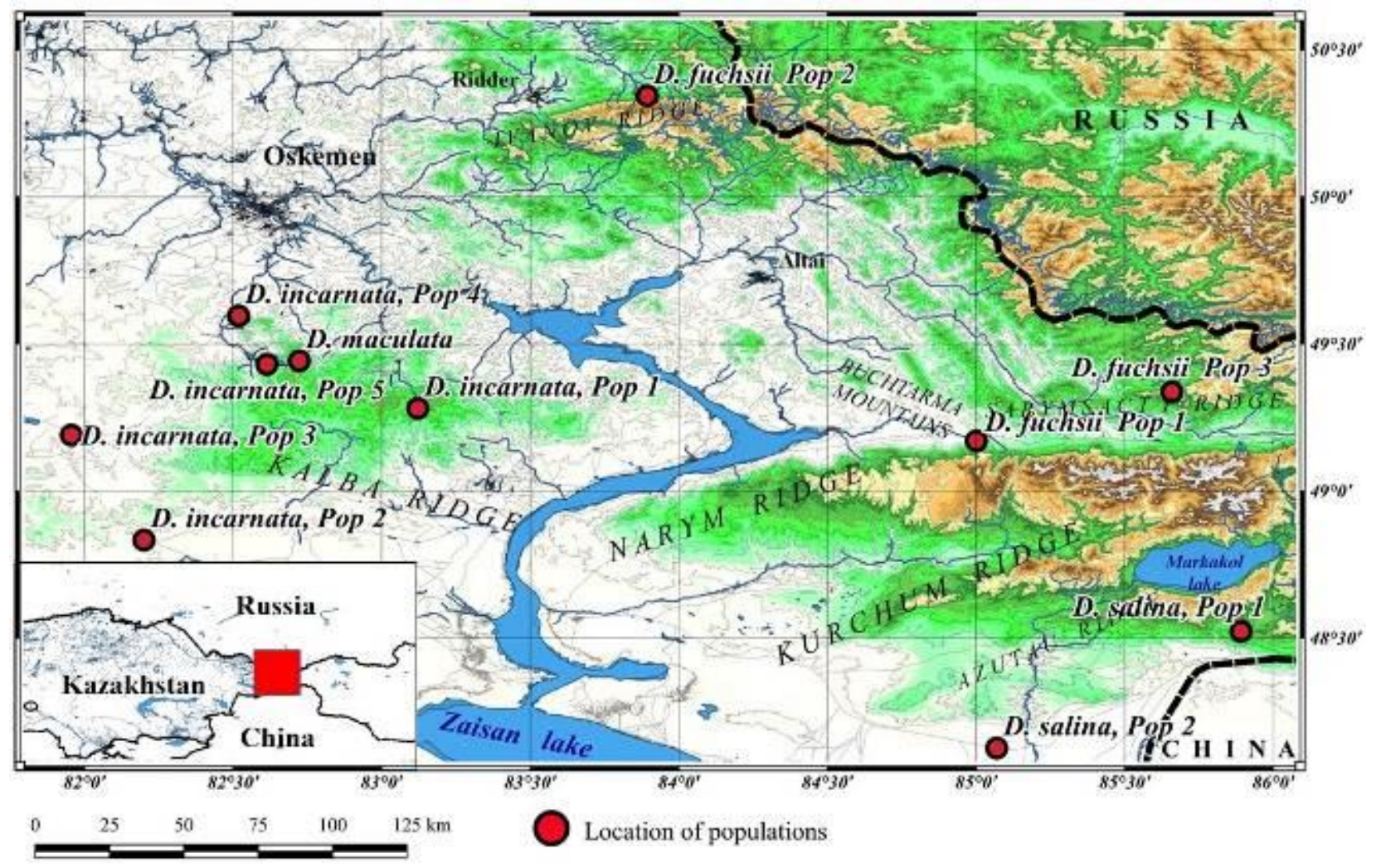

Figure 1. Locations of the examined populations of species of Dactylorhiza Necker ex Nevski in the Altai region of Kazakhstan 
Table 1. Ecological and phytocenotic characteristics of the locations of the studied populations of Dactylorhiza

\begin{tabular}{|c|c|c|c|c|c|c|c|}
\hline $\begin{array}{c}\text { Species, } \\
\text { population }\end{array}$ & Location & $\begin{array}{c}\text { Geographical } \\
\text { coordinates }\end{array}$ & $\mathbf{L}$ & $\mathbf{F}$ & $\mathbf{R}$ & $\mathbf{N}$ & Habitat \\
\hline $\begin{array}{l}\text { Dactylorhiza } \\
\text { fuchsii (Druce) } \\
\text { Soo, Pop 1 }\end{array}$ & $\begin{array}{l}\text { Bukhtarma mountains, vicinity of } \\
\text { Maimyr Village, Batash tract, valley } \\
\text { of Naryn river }\end{array}$ & $\begin{array}{l}49.17055 \mathrm{E} \\
85.00027 \mathrm{~N} \\
739 \mathrm{~m} \text { a.s.l. }\end{array}$ & $3-4$ & $3-4$ & 3 & 3 & $\begin{array}{l}\text { Birch forest, } \\
\text { underneath tree } \\
\text { canopy }\end{array}$ \\
\hline $\begin{array}{l}\text { D. fuchsii (Druce) } \\
\text { Soo, Pop } 2\end{array}$ & $\begin{array}{l}\text { Ivanov ridge, southwestern foothills, } \\
\text { tract "Gray meadow", Bolshaya } \\
\text { Poperechka river valley }\end{array}$ & $\begin{array}{l}50.34388 \mathrm{E} \\
83.89277 \mathrm{~N} \\
1212 \mathrm{~m} \text { a.s.l. }\end{array}$ & 4 & 4 & 4 & 3 & $\begin{array}{l}\text { Fir-birch edge, moist } \\
\text { glade, mossy }\end{array}$ \\
\hline $\begin{array}{l}\text { D. fuchsii (Druce) } \\
\text { Soo, Pop } 3\end{array}$ & $\begin{array}{l}\text { Sarymsakty Ridge, north-western } \\
\text { foothills, near Topkain Village }\end{array}$ & $\begin{array}{l}49.33694 \mathrm{E} \\
85.65777 \mathrm{~N} \\
912 \mathrm{~m} \text { a.s.l. }\end{array}$ & $3-4$ & 3 & 3 & 3 & $\begin{array}{l}\text { Creek valley, mixed } \\
\text { forest }\end{array}$ \\
\hline $\begin{array}{l}\text { D. salina (Turcz. } \\
\text { ex Lindl.) Soo, Pop } \\
1\end{array}$ & $\begin{array}{l}\text { Azutau ridge, Mramorny pass, } \\
\text { northeastern foothills, Karagashty } \\
\text { tract }\end{array}$ & $\begin{array}{l}48.52277 \mathrm{E} \\
85.89055 \mathrm{~N} \\
1289 \mathrm{~m} \text { a.s.l. }\end{array}$ & $4-5$ & 4 & 4 & $2-3$ & Forb meadow \\
\hline $\begin{array}{l}\text { D. salina (Turcz. } \\
\text { ex Lindl.) Soo, Pop } \\
2\end{array}$ & $\begin{array}{l}\text { Azutau ridge, foothills of the } \\
\text { southeastern slope, southwest of } \\
\text { Markakol Village }\end{array}$ & $\begin{array}{l}48.12611 \mathrm{E} \\
85.06888 \mathrm{~N} \\
465 \mathrm{~m} \text { a.s.l. }\end{array}$ & 5 & $3-5 u$ & 4 & 2 & $\begin{array}{l}\text { Flooded saline } \\
\text { meadow }\end{array}$ \\
\hline $\begin{array}{l}\text { D. maculata (L.) } \\
\text { Soo }\end{array}$ & $\begin{array}{l}\text { Kalba highlands, eastern part, } \\
\text { southwestern periphery of Koktau } \\
\text { mountains, near Algabas Village }\end{array}$ & $\begin{array}{l}49.44277 \mathrm{E} \\
82.72277 \mathrm{~N} \\
891 \mathrm{~m} \text { a.s.l. }\end{array}$ & 4 & $4-5$ & 3 & 2 & Swampy meadow \\
\hline $\begin{array}{l}\text { D. incarnata (L.) } \\
\text { Soo, Pop } 1\end{array}$ & $\begin{array}{l}\text { Kalba highlands, eastern part, } \\
\text { mountain pass Umysh }\end{array}$ & $\begin{array}{l}49.280556 \mathrm{E} \\
83.121111 \mathrm{~N} \\
1230 \mathrm{~m} \text { a.s.l. }\end{array}$ & $4-5$ & $3-4$ & 3 & 2 & $\begin{array}{l}\text { Creek valley, } \\
\text { herbaceous meadow }\end{array}$ \\
\hline $\begin{array}{l}\text { D. incarnata (L.) } \\
\text { Soo, Pop } 2\end{array}$ & $\begin{array}{l}\text { Kalba highlands, southwestern } \\
\text { foothills of the southeastern } \\
\text { outskirts, northern spurs of the } \\
\text { Karazhal mountains, Kokpektinka } \\
\text { river valley }\end{array}$ & $\begin{array}{l}48.833333 \mathrm{E} \\
82.200278 \mathrm{~N} \\
600 \mathrm{~m} \text { a.s.l. }\end{array}$ & 4 & 3 & 3 & 2 & $\begin{array}{l}\text { Swampy lowland, } \\
\text { edge of willow and } \\
\text { birch forest, under } \\
\text { the canopy of sparse } \\
\text { bushes }\end{array}$ \\
\hline $\begin{array}{l}\text { D. incarnata (L.) } \\
\text { Soo, Pop } 3\end{array}$ & $\begin{array}{l}\text { Kalba highlands, eastern part, } \\
\text { southwestern spurs, foot of the } \\
\text { Saryzhal ridge, Shar river valley, } \\
\text { near Kalbatau Village }\end{array}$ & $\begin{array}{l}49.190278 \mathrm{E} \\
81.955833 \mathrm{~N} \\
525 \mathrm{~m} \text { a.s.l. }\end{array}$ & 5 & 3 & 3 & $2-3$ & $\begin{array}{l}\text { Wet meadows, damp } \\
\text { depressions and } \\
\text { willow forest edges }\end{array}$ \\
\hline $\begin{array}{l}\text { D. incarnata }(\mathrm{L} .) \\
\text { Soo, Pop } 4\end{array}$ & $\begin{array}{l}\text { Kalba highlands, Koktau mountains, } \\
\text { Shat tract, near Toganas Village }\end{array}$ & $\begin{array}{l}49.59583 \mathrm{E} \\
82.51861 \mathrm{~N} \\
634 \mathrm{~m} \text { a.s.l. }\end{array}$ & 4 & $4-5$ & 3 & 3 & $\begin{array}{l}\text { Mountain valley along } \\
\text { stream, mossy cover }\end{array}$ \\
\hline $\begin{array}{l}\text { D. incarnata }(\mathrm{L} .) \\
\text { Soo, Pop } 5\end{array}$ & $\begin{array}{l}\text { Kalba highlands, southwestern part } \\
\text { of the Koktau mountains, Sibin } \\
\text { depression, Lake Tortkara area }\end{array}$ & $\begin{array}{l}49.43083 \mathrm{E} \\
82.61388 \mathrm{~N} \\
791 \mathrm{~m} \text { asl. }\end{array}$ & 5 & $4-5 u$ & 3 & 2 & $\begin{array}{l}\text { Creek valley, flood } \\
\text { meadow }\end{array}$ \\
\hline
\end{tabular}

Note: Ecological scales (Landolt 1977): L: illuminance scale: 1. completely shady plant, often growing in conditions less than 3\% of full light; 2 . mostly shady plant (more often at $10 \%$ of full illumination); 3. penumbra plant (at a relative illumination of more than $10 \%$ ); 4 . semi-light (often in full light, but sometimes with some shading); 5. completely light plant, unable to tolerate shading. F: humidity scale: 1. on very dry soils, indicator of dry habitats; 2 . on dry soils, avoids very dry and very wet soils; 3 . on medium dry to moist soils; 4 . on wet to damp soils; 5 . on soils saturated with water, avoids moderately moist habitats; $5 \mathrm{w}$. on very damp soils after rain; $5 \mathrm{u}$. in flooded areas; $5 \mathrm{~s}$. plants with leaves floating in the water; $5 \mathrm{i}$. plants live in water, but most of their leaves are above water. R: soil acidity scale: 1. on very acidic soils ( $\mathrm{pH}$ less than 4.5); 2 . on acidic soils ( $\mathrm{pH} 3.5-5.6$ ); 3. on slightly acidic soils ( $\mathrm{pH} 4,5-7,5$ ), never on very acidic, but sometimes on neutral and slightly alkaline soils; 4. on alkaline soils ( $\mathrm{pH}$ 5.5-8.0); 5. only on alkaline soils ( $\mathrm{pH}$ above 6.5); $\mathrm{x}$. on very acidic and alkaline soils, often avoids medium conditions, as it does not withstand competition with other species. N. soil nutrient richness scale (especially nitrogen): 1 . on very rich soils; 2 . on poor soils; 3 . on soils from medium-dry to medium-rich; 4. on rich soil; 5: on soil rich (especially in nitrogen), never found on poor

Comparison of the average values of the population traits is shown in the Supplement. For each population, the labellum shape index was calculated (Heslop-Harrison 1951), according to the formula:

$$
I L=\frac{2 * \text { LL }}{\text { LBS + LLL } . ~}
$$

Data for principal component analysis (PCA), correlation analyses and the construction of a dendrogram of similarity (cluster analysis) were processed in the Rstudio program (Version 1.3.1093). ANOVA analysis was carried out using the STATISTICA 10.0 program. Flower structure schemes were built in Autodesk AutoCAD 2016.

\section{RESULTS AND DISCUSSION}

Species boundaries and rank of individual specimens can more accurately be determined by comparing the characters displayed by representatives of entire populations and by identifying groups of similar and closely related populations (Kirillova 2018). Statistical analysis of our results on flower structure of the four studied species of Dactylorhiza revealed significant and stable differences between them.

Populations of D. fuchsii (Figure 3.A) were identified from three habitats (Figure 1). Environmental conditions there ranged from deciduous forest to edges of mixed forest (700-1200 $\mathrm{m}$ a.s.l.). The insolation in these populations 
ranged from partial shade to scattered light at forest edges. There is a direct effect of amount of light on the length of labellum middle lobe and length of lateral sepals (Figure 4.A). The plots were characterized by moisture ranging from medium dry to moist soils. Soils are slightly acidic, less often alkaline with an average richness of nutrients (Table 1). An inverse correlation of soil richness was noted on the length of the labellum middle lobe.

Labellum shape index is 1.4-1.8 (Supplement). Distinctive typological features (Figure 5A) are the length of ovary $9.470-10.825 \mathrm{~mm}$ and length of the labellum middle lobe $2.515-4.927 \mathrm{~mm}$. A direct correlation could be observed between the length of labellum and length of labellum middle lobe, and between the length of labellum and length of the lateral sepals (Figure 4.A).

Dactylorhiza salina (Figure 3.B) in the Kazakhstan Altai is typically found growing on the Azutau ridge and its foothills (Figure 1). Two, spatially distant populations of the species were identified. The ecological optimum of the species varies between flooded saline and damp forb meadows at an altitude of 465-1289 m a.s.1. (Table 1). Soil moisture significantly affects the length of spur and the dorsal sepal width (Figure 4.B). Populations of the species occupy semi-light or fully insolated areas with moist soils, often in flooded areas. Insolation significantly affects the length of spur and the width of the dorsal sepal. Soils are alkaline, at $\mathrm{pH}$ 5.5-8.0, but poor in nutrients. Soil acidity and soil richness are inversely correlated with the dorsal sepal width (Figure 4.B).

The labellum shape index for two of the populations of D. salina was 1.1-1.2 (Supplement). The distinctive characteristic features (Figure 5B) are length of spur 9.805$13.817 \mathrm{~mm}$, and length of the lateral lobe of the labellum $6.905-7.050 \mathrm{~mm}$. A high correlation is observed between the length of the lateral lobe of the labellum and the length from the base of the spur entrance to the base of the sinus (Figure 4.B).

Individuals of D. maculata (Figure 3.C) in the Kazakhstan Altai are concentrated in a single isolated population in the southwestern periphery of the Koktau mountains of the Kalba ridge (Figure 1). The plants occupy a swampy meadow at an altitude of $891 \mathrm{~m}$ a.s.l. The area is characterized by little shading and damp or water-soaked soil. The soil substrate is slightly acidic and poor in nutrients (Table 1).

The labellum shape index in D. maculata is 1.3 (Supplement). Distinctive features in the morphometric structure (Figure 5C) are width of labellum at base 2.7-4.1 $\mathrm{mm}$, length of spur 6.9-9.5 mm, and length of ovary 12.6$17.0 \mathrm{~mm}$. High correlations are observed between length of labellum and length of lateral lobe of the labellum, as well as width of lateral lobe of the labellum and width of labellum. An inverse correlation has been noted between the length of the spur and the width of the lateral sepals (Figure 4.C).

Populations of D. incarnata (Figure 3.D) were identified in five locations (Figure 1), ranging from mountain stream valleys to flooded meadows at an altitude of 525-1230 $\mathrm{m}$ a.s.1. The areas occupied by these plants are fully insolated, rarely with little shading. The plots are characterized by a large variation in the degree of soil moisture: from moist soils to flooded areas (Table 1). Soil moisture appears to directly affect length of the dorsal sepal and width of spur (Figure 4.D). The soil substrate is slightly acidic or neutral and poor in nutrients. An inverse correlation is observed for the width of the dorsal sepal with decreasing soil acidity (Figure 4.D).

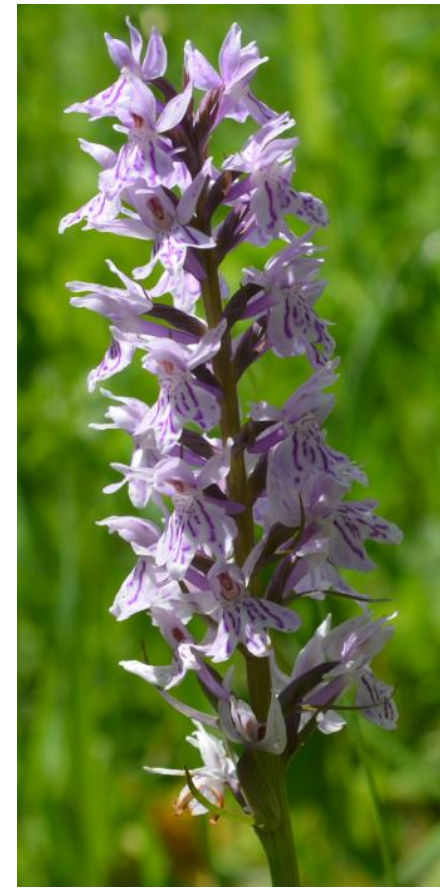

A

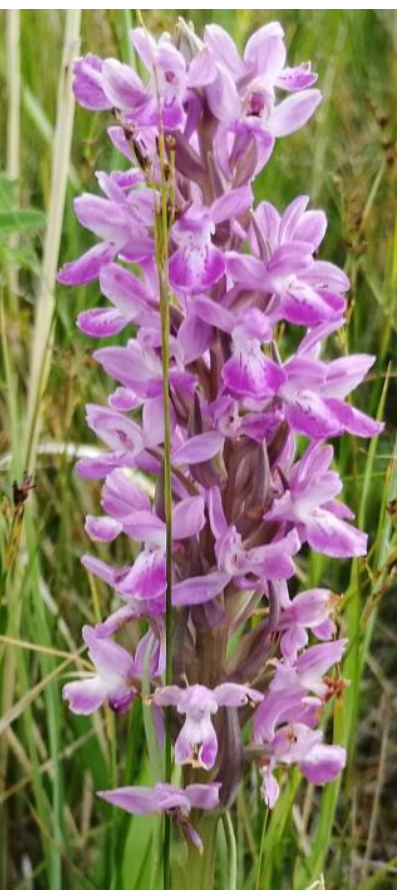

B

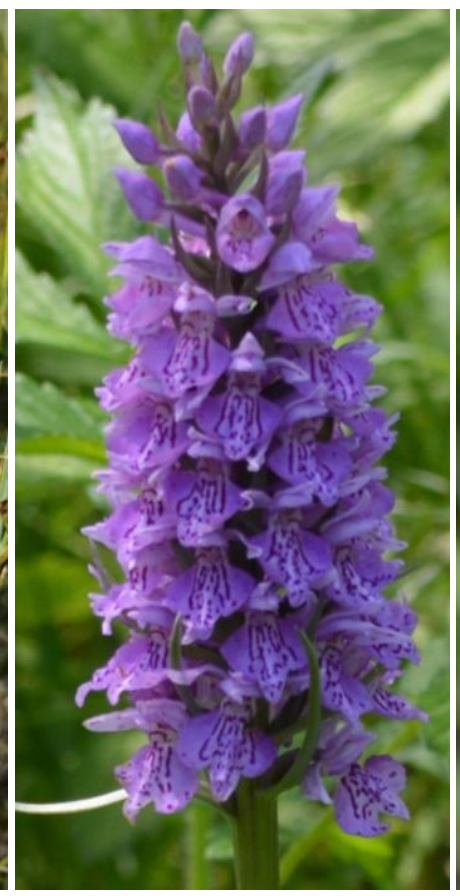

C

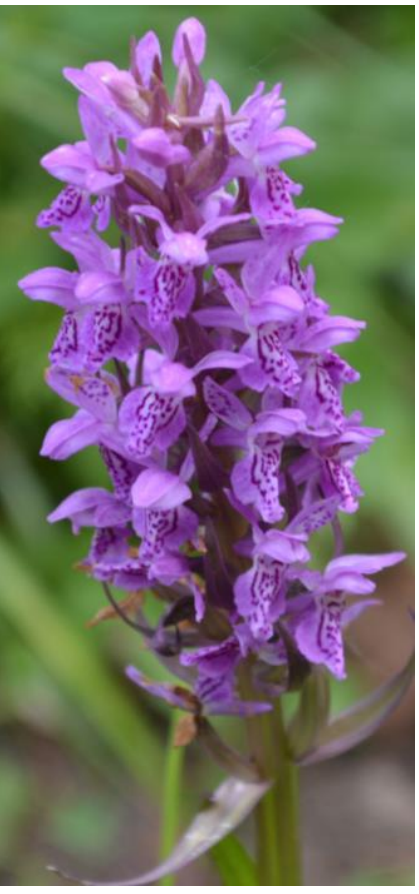

D

Figure 3. Inflorescences of: A. Dactylorhiza fuchsii; B. D. salina; C. D. maculata; D. D. incarnata. 


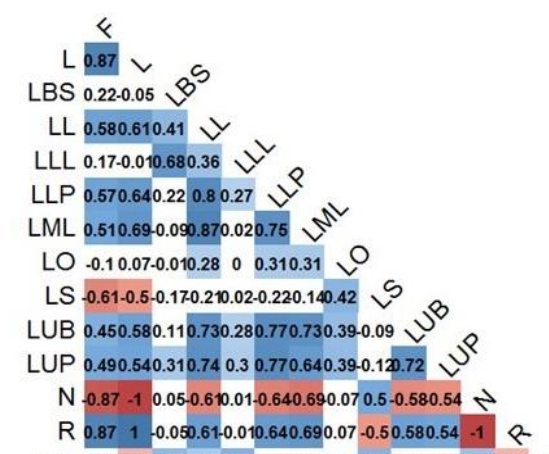

WL $-0.190 .350 .410 .310 .450 .150 .110 .250 .430 .090 .20 .35-0.35$ N WLB -0.120.240.410.140.26-0.010.070.080.030.06 0.1 0.24-0.240.43 $N^{2}$ WLL - $0.240 .350 .280 .250 .370 .180 .120 .280 .330 .110 .170 .35-0.350 .740 .44 W^{2}$ WLP 0.2 0.220.050.230.090.250.23-0.140.120.26 0.2 -0.220.22-0.10.03-0.03 $\mathbb{N}^{2}$ WML - 0.140.510.39-0.20.25-0.310.430.270.02-0.320.180.51-0.510.420.340.330.06

WS - $0.020 .070 .080 .070 .110 .180 .030 .310 .040 .150 .090 .07-0.070 .230 .180 .23-0.110 .04 N^{S}$ WUB 0.360.32-0.040.240.110.210.28-0.060.040.240.11-0.320.32-0.080.050.150.19-0.130.09 $\mathrm{N}^{\mathrm{V}}$ WUP $0.280 .260 .370 .33 \quad 0.40 .290 .16-0.140 .340 .290 .28-0.260 .26-0.010 .170 .120 .390 .140 .02-0.01$

\section{A}
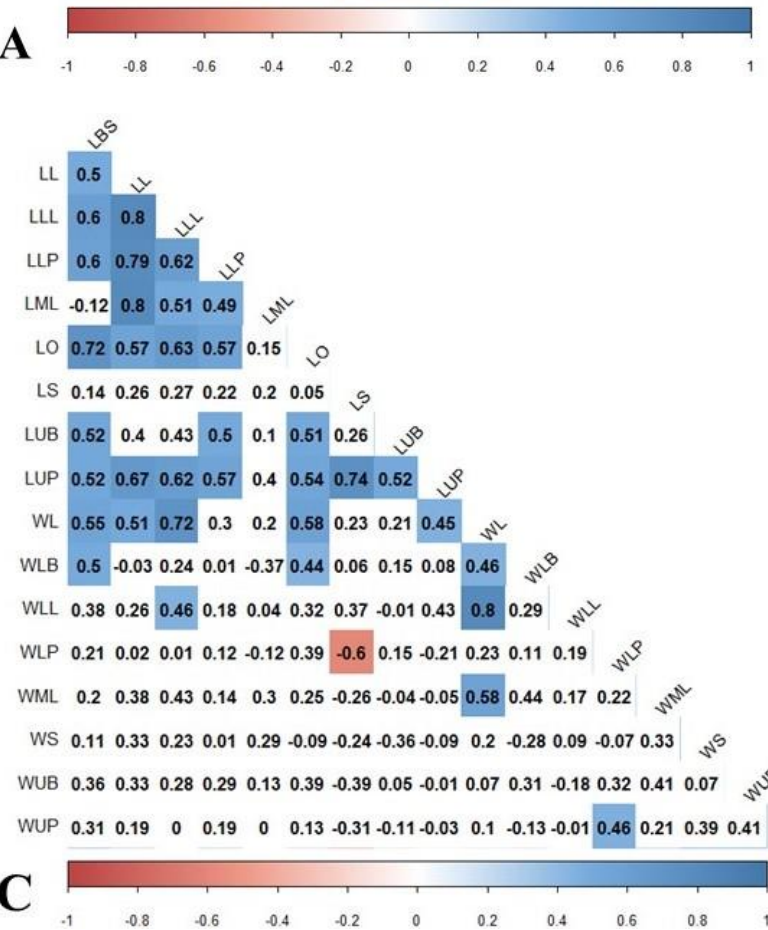

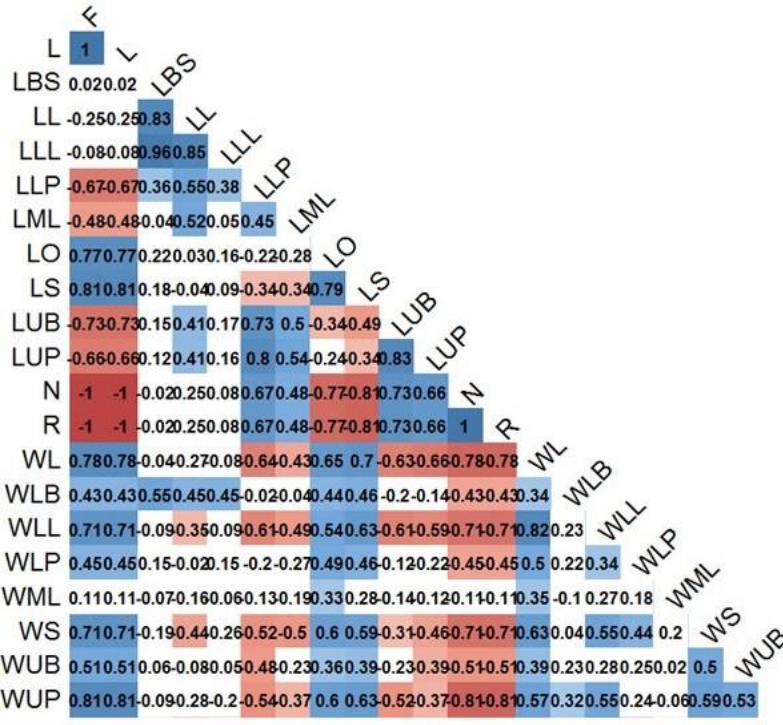

B
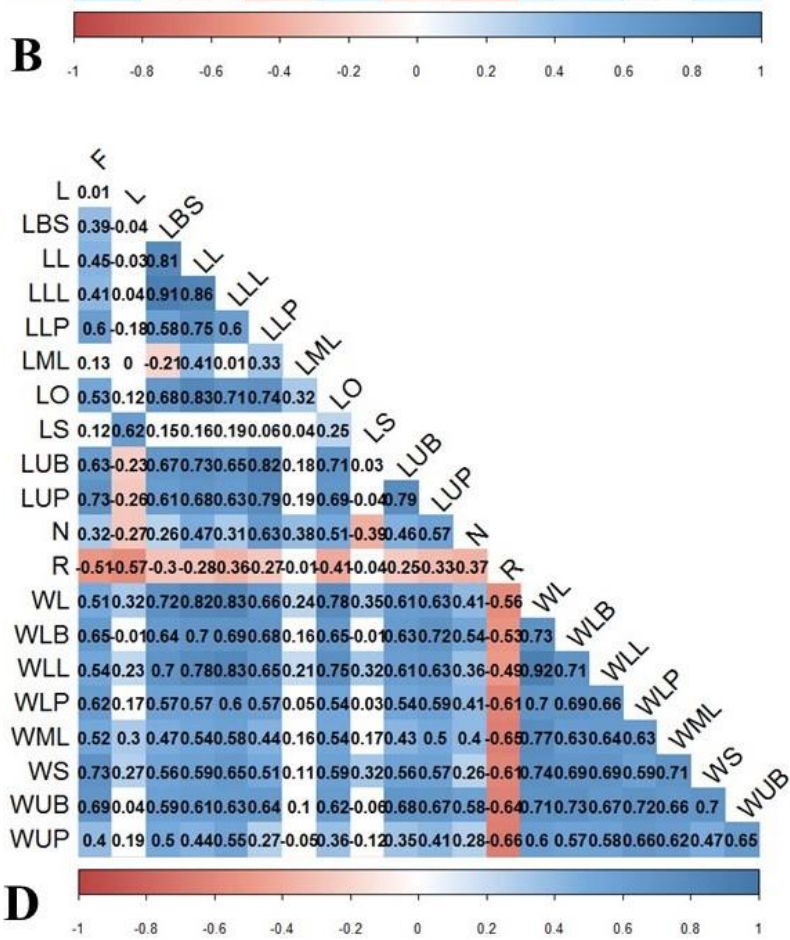

Figure 4. Correlation between morphometric characters of flowers and environmental factors: A. D. fuchsii; B. D. salina; C. D. maculata; D. D. incarnata

The labellum shape index for the five populations of $D$. incarnata was recorded as 1.2-1.4 (Supplement). Distinctive specific features of the structure of flowers (Figure 5D) are: width of labellum at base 2.320-4.163 mm and length of labellum middle lobe $1.340-2.278 \mathrm{~mm}$. Correlations were noted between the length of the lateral lobe of the labellum and length from the base of the labellum entrance to the base of the sinus, width of lateral lobe of the labellum and width of labellum (Figure 4.D).

Analysis of variance (ANOVA) (Table 2) revealed a significant effect of environmental factors on all morphological characters of $D$. incarnata populations.

The environmental effect on $D$. fuchsii populations is manifested in all morphological traits, except for the width of the lateral sepals and width of spur. The environment affects all morphometric characters of $D$. salina, except for length of labellum, length of lateral lobe of the labellum, length from the base of labellum entrance to base of sinus, and width of labellum middle lobe. The effect of the environment on the phenotype of $D$. maculata cannot be determined, due to the singularity of the population and habitat.

The PCA plot for species differences (Figure 6) suggests an arrangement of populations with an influence of geography and environmental conditions on the morphology of the studied species. In addition, some isolation from other populations of the studied species was 
revealed for the second population of $D$. fuchsii, the fourth population of $D$. incarnata, and the population of $D$. salina.

PCA (Figure 7) demonstrates differences in representatives of various populations or species, and the similarity within or closely related populations. An insignificant isolation of several samples from other individuals was recorded for the second population of $D$. fuchsii and the first population of $D$. salina.

The cluster analysis was built on the basis of the average indicators of the characteristics (Supplement). The dendrogram (Figure 8) shows a graphical representation of the results of the morphometric measurements. The dendrogram divides all populations into 4 main clusters.

Table 2. Results of ANOVA

\begin{tabular}{llcccc}
\hline \multicolumn{1}{c}{ Species } & \multicolumn{1}{c}{ Factor } & df & Ss & MS & F \\
\hline D. fuchsii & Environment & 2 & 3.194 & 1.597 & $17.52^{* * *}$ \\
D. incarnata & Genotype & 19 & 2.538 & 0.134 & 0.724 \\
D. salina & Environment & 4 & 10.522 & 2.631 & $17.19 * * *$ \\
& Genotype & 19 & 3.102 & 0.163 & 1.119 \\
& Environment & 1 & 4.649 & 4.649 & $56.57 * * *$ \\
& Genotype & 19 & 2.279 & 0.12 & 0.8960 \\
\hline
\end{tabular}

Note: Ss: sum of squares, df: degree of freedom, MS: mean square, F: Fisher's coefficient, P: value; $* \mathrm{P}<0.01 ; * * \mathrm{P}<0.05 ; * * * \mathrm{P}<0.001$

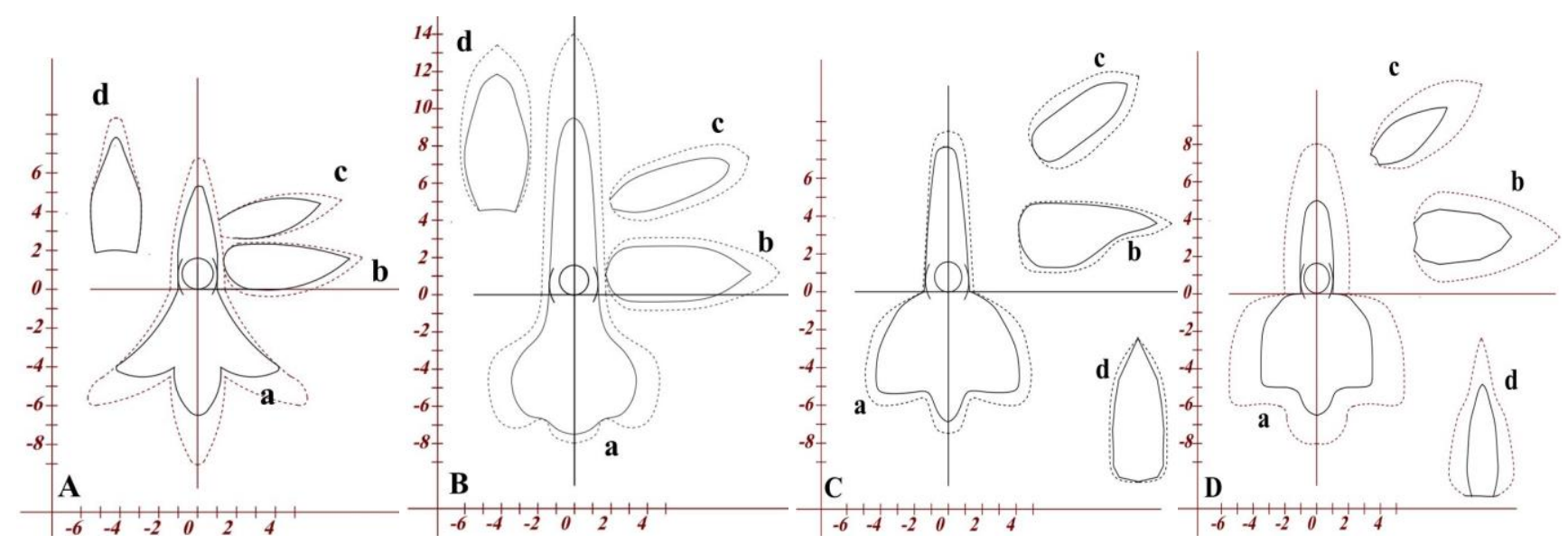

Figure 5. Schemes of the flower structure based on the average metrics of characteristics (mm): A. Dactylorhiza fuchsii (Druce) Soo; B. D. salina (Turcz. ex Lindl.) Soo; C. D. maculata (L.) Soo; D. D. incarnata (L.) Soo; a. labellum-spur, b. lower petal of the outer circle of the perianth, c. upper petal of the outer circle of the perianth, d. upper petal of the internal circle of the perianth; maximum sizes are marked by a dotted line.

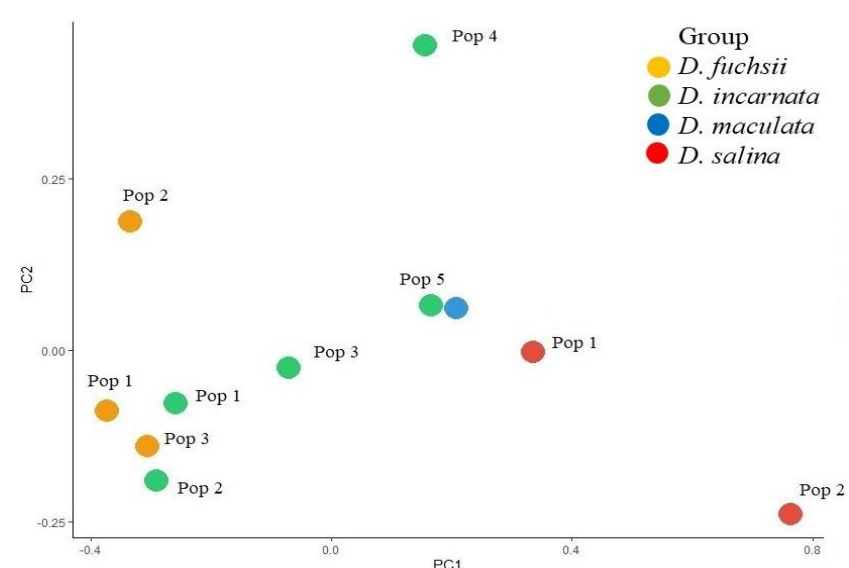

Figure 6. Principal component analysis (PCA) for species differences of Dactylorhiza based on metric characteristics of flower structure

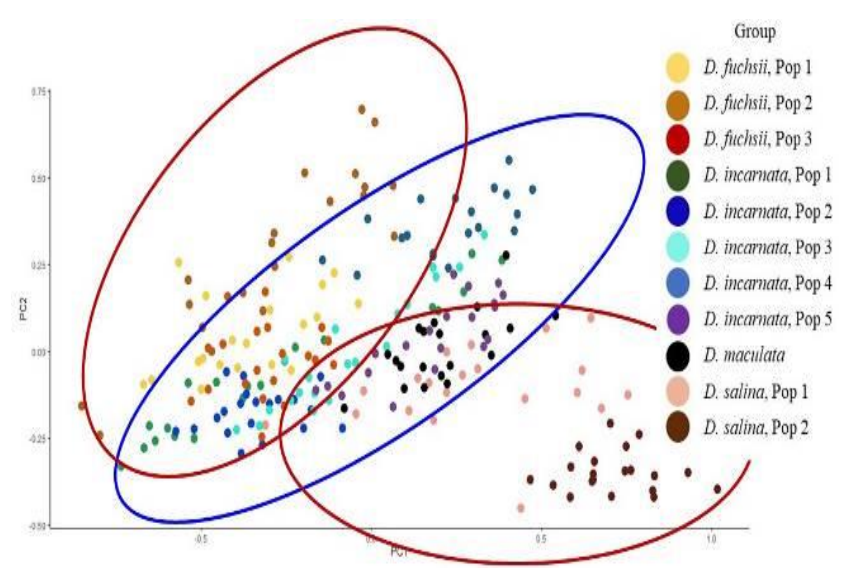

Figure 7. PCA for population differences in Dactylorhiza based on metric characteristics of flower structure 


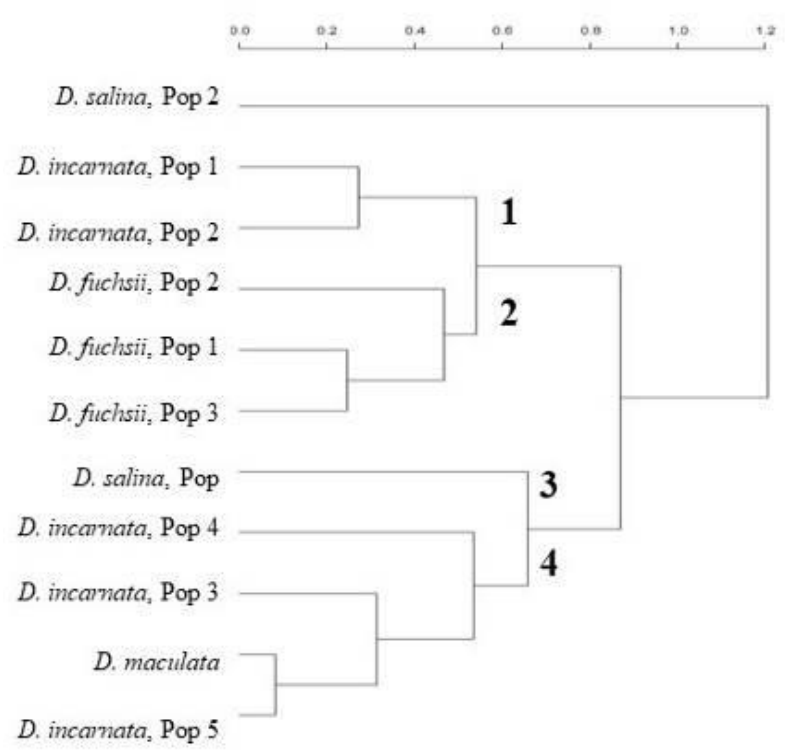

Figure 8. Hierarchical clustering of populations of species of Dactylorhiza based on the average values of metric features of flower structure

\section{Discussion}

In an earlier study, Kirillova (2018) studied 16 populations of four species (D. fuchsii, D. maculata, D. incarnata, and D. traunsteineri) based on 13 diagnostic features of flowers. We here studied 11 populations of four Dactylorhiza species from the Kazakhstan Altai, analyzing the morphometric characteristics of flowers using 17 metric features of flowers (Figure 2). Additional attention was paid to the following characters: width of labellum at base, width of the dorsal sepal, width of the lateral sepals, width of labellum middle lobe, length and width of the petals. This study's results overlap with Shipunov (2004) and Ståhlberg (2008) work, where the morphometry of similar species was studied and the labellum shape index was used as the main parameter. This study qualitatively complements the earlier studies on Dactylorhiza in Kazakhstan (Flora of Kazakhstan 1958; Averyanov 1988, 1989, 1990b), where only length of labellum, length of spur and width of spur were used for taxonomy of metric flower features.

The established correlation between environmental conditions and morphological characteristics (Figure 4) showed a strong environmental effect on the morphometric characteristics of flowers. The main environmental factors were insolation and soil moisture. ANOVA analysis for "Genotype-Environment" dependence confirmed the significant influence of the specific natural habitats on the studied species.

PCA data on species differences (Figure 6) confirm the influence of geography and environmental conditions on the morphology of the studied species. Thus, according to the PCA, the second population of D. fuchsii is noticeably distant from other populations of the species in terms of morphological characteristics. According to the schematic map (Figure 1), this population is geographically distant and differs in altitudal zonal affiliation. The fourth population of D. incarnata, is separated from other populations of the species by PC2. This was inpart due to the northernmost location (Figure 1) and shaded growing conditions (Table 1), which apparently leads to larger flowers among the populations of the species. The second population of $D$. salina is separated from all other populations by PC1. Perhaps, in addition to being a unique species, this may be due to the southeastern remoteness of its occurrence (Figure 1) and the lowest altitudinal zoning (465 $\mathrm{m}$ asl.).

The PCA of population differences (Figure 7) showed high intraspecific diversity. The studied populations were conditionally divided into three groups (enclosed in ellipses in Figure 7). The first group consists of the populations of $D$. fuchsii; the second group of populations of $D$. incarnata; and the third group of the population of $D$. salina. Thus, the populations of D. fuchsii, D. maculata, and D. incarnata differ markedly in $\mathrm{PC} 1$, and the populations of D. salina in PC2 also confirm the PCA in terms of species diversity.

Cluster analysis (Figure 8) grouped the studied populations into 4 main clusters. The first and second populations of $D$. fuchsii are closely related and stable. A separate cluster 1 is formed in the dendrogram, which confirms the PCA data. Populations of D. fuchsii differ from others both in morphology and in their ecology and form a separate cluster 2. The third, fourth, and fifth populations of $D$. incarnata and the only population of $D$. maculata form cluster 4. Geographically, these populations are located close to each other (Figure 1), occupying the central part of the Kalba ridge under the same ecological conditions. Two populations of $D$. salina form cluster 3 and the outgroup, since the morphological differences of the species differ significantly from other species of the genus Dactylorhiza. Populations of $D$. salina grow in isolation in the southeast of the Kazakhstan Altai, which also confirms the species' isolation into a separate cluster.

Finding different species in the same clusters and finding populations of the same species in different clusters does not mean that flower morphometry is less useful to distinguish between Dactylorhiza species. In seems obvious that the ecological habitat conditions have a significant impact on morphometric characters. Thus, the specific ecological conditions of the Kazakhstan Altai (high continental climate, short hydration period, xerophytic of flora) have a significant impact on the plants' features.

The particular living conditions of the ecotypes of the species of Dactylorhiza in the Kazakhstan Altai impose a significant effect on their morphometric structure, which may vary considerably from those prevailing in Siberia (Efimov 2020) or Central Asia (Akzhygitova et al. 2003).

In addition, it is important to take into account the diversity of optimal ecological conditions in a limited area in the studied region: from flooded meadows and river valleys to the edges of dark coniferous and mixed forests. Specimens growing in shade are usually larger than meadow ecotypes, which are usually associated with a richer substrate (Table 1). There is also a clear effect of altitudinal zoning of the habitats: mountain ecotypes are 
larger, but shorter than plants growing in the plains at lower altitudes.

In summary, samples of four species of the genus Dactylorhiza were collected in the Kazakhstan Altai. Particular metric features were identified that allow to distinguish the four closely related species. The morphometric structure of flowers was studied using 17 metric parameters in generative individuals of 11 populations. A significant effect of the environment on the morphometric characters of flowers was proven. The most variable and stable traits, as well as distinctive features for each species, were established. The PCA for species and population diversity showed a high degree of morphological diversity of ecotypes. Cluster analysis graphically displayed the structure of the population diversity of the studied species. Structural schemes were drawn up. The reported features can serve as a basis to further elaborate on the taxonomy of the genus Dactylorhiza in the Kazakhstan Altai region and for future work on these plants occurring in Kazakhstan as a whole.

\section{ACKNOWLEDGEMENTS}

Financial support was granted by the scientific program from the Ministry of Education and Science of the Republic of Kazakhstan for 2021-2022. The authors are grateful to Dr. Yu.A. Kotukhov, Dr. N.A. Ryabushkina, Yu.A. Genievskaya, and O.A. Lagus for their help in preparing the manuscript and valuable guidance. We thank Theodor C.H. Cole for English language editing and valuable advice.

\section{REFERENCES}

Akbulut MK, Şenel G, Şeker ŞS. 2020. Comparison of labellum and spur papillae in Dactylorhiza (Orchidaceae) from Anatolia. Brazilian J Bot 43 (2): 367-377. DOI: 10.1007/s40415-020-00597-5

Akbulut MK, Şenel G. 2016. The seeds micromorphology and morphometry of certain Dactylorhiza (Orchidaceae) species distributed in Turkey. Rend Lincei Sci Fis 27: 679-686. DOI: 10.1007/s12210-016-0549-z

Akzhygitova NI, Breckle S-W. et al. 2003. Botanical geography of Kazakhstan and Middle Asia (desert region). St. Petersburg.

Averyanov LV. 1988. Synopsis of the genus Dactylorhiza Neck. ex Nevski (Orchidaceae), 1. News of The Taxonomy of Higher Plants 25: 48-67. [Russian]

Averyanov LV. 1989. Synopsis of the genus Dactylorhiza Neck. ex Nevski (Orchidaceae), 2. News of The Taxonomy of Higher Plants 26: 47-57. [Russian]

Averyanov LV. 1990a. A review of the genus Dactylorhiza. In: Arditi J (Ed.). Orchid Biology: Reviews and Perspectives V. Timber Press, Oregon.

Averyanov LV. 1990b. Synopsis of the genus Dactylorhiza Neck. ex Nevski (Orchidaceae), 3. News of The Taxonomy of Higher Plants 27: 32-62. [Russian]

Aybeke M, Sezik E, Olgun G. 2010. Vegetative anatomy of some Ophrys, Orchis and Dactylorhiza (Orchidaceae) taxa in Trakya region of Turkey. Flora-Morphology, Distribution, Functional Ecology of Plants 205 (2): 73-89. DOI: 10.1016/j.flora.2008.11.009

Balao F, Trucchi E, Wolfe TM, Hao B-H, Lorenzo MT, Baar J, Sedman L, Kosiol C, Amman F, Chase MW, Hedrén M, Paun O. 2017. Adaptive sequence evolution is driven by biotic stress in a pair of orchid species (Dactylorhiza) with distinct ecological optima. Mol Ecol 26 (14): 3649-3662. DOI: $10.1111 / \mathrm{mec} .14123$
Bateman RM, Farrington OS. 1989. Morphometric comparison of populations of Orchis simia Lam. (Orchidaceae) from Oxfordshire and Kent. Bot $\mathrm{J}$ the Linnean Soc 100 (3): 205-218. DOI: 10.1111/j.1095-8339.1989.tb01718.x

Bateman RM, Denholm I. 1989. A reappraisal of the British and Irish dactylorchids, 3. The spotted-orchids. Watsonia 17: 319-349.

Bateman RM, Rudall PJ. 2006. Evolutionary and morphometric implications of morphological variation among flowers within an inflorescence: A case-study using European orchids. Ann Bot 98 (5): 975-993. DOI: 10.1093/aob/mcl191

Bateman RM, Rudall PJ. 2018a. Clarified relationship between Dactylorhiza viridis and Dactylorhiza iberica renders obsolete the former genus Coeloglossum (Orchidaceae: Orchidinae). Kew Bull 73 (1): 4. DOI: $10.1007 / \mathrm{S} 12225-017-9728-Z$

Bateman RM, Hollingsworth PM, Preston J, Yi-Bo L, Pridgeon AM, Chase MW. 2003. Molecular phylogenetics and evolution of Orchidinae and selected Habenariinae (Orchidaceae). Bot J Linnean Soc 142 (1): 1-40. DOI: 10.1046/j.1095-8339.2003.00157.x

Bateman RM, Murphy AR, Hollingsworth PM, Hart ML, Denholm I, Rudall PJ. 2018b. Molecular and morphological phylogenetics of the digitate-tubered clade within subtribe Orchidinae ss (Orchidaceae: Orchideae). Kew Bull 73 (4): 1-30. DOI: 10.1007/s12225-018-97821

Baytulin IO, Kotukhov YA. 2011. Flora of vascular plants of Kazakhstan Altai. Almaty. [Russian]

Brandrud MK, Baar J, Lorenzo MT, Athanasiadis A, Bateman RM, Chase MW, Hedrén M, Paun O. 2020. Phylogenomic relationships of diploids and the origins of allotetraploids in Dactylorhiza (Orchidaceae). Syst Biol 69 (1): 91-109. DOI: 10.1093/sysbio/syz035

Delforge P. 2001. Guide des orchidees d'Europe, d'Afrique du Nord et du Proche-Orient, 2nd edn. Delachaux et Niestle, Lausanne.

Devos N, Raspé O, Oh SH, Tyteca D, Jacquemart AL. 2006. The evolution of Dactylorhiza (Orchidaceae) allotetraploid complex: Insights from nrDNA sequences and cpDNA PCR-RFLP data. Mol Phylogenet Evol 38 (3): 767-778. DOI: 10.1016/j.ympev.2005.11.013

Dufrêne M, Gathoye JL, Tyteca D. 1991. Biostatistical studies on western European Dactylorhiza (Orchidaceae) - the D. maculata group. Plant Syst Evol 175 (1): 55-72. DOI: 10.1007/BF00942145

Efimov PG. 2020. Orchids of Russia: Annotated checklist and geographic distribution. Nat Conserv Res 5 (1): 1-18. DOI: 10.24189/ncr.2020.018

Efimov PG, Philippov EG, Krivenko DA. 2016. Allopolyploid speciation in Siberian Dactylorhiza (Orchidaceae, Orchidoideae). Phytotaxa 258 (2): 101-120. DOI: 10.11646/phytotaxa.258.2.1

Flora of Kazakhstan. 1958. Volume II (team of authors). Alma-ata: Publishing house of the Academy of Sciences of the Kazakh SSR. [Russian]

Gamarra R, Galan P, Pedersen HA, Ortúñez E, Sanz E. 2015. Seed micromorphology in Dactylorhiza Necker ex Nevski (Orchidaceae) and allied genera. Turkish J Bot 39 (2): 298-309. DOI:10.3906/bot1401-66

Givnish TJ, Spalink D, Ames M, et al. 2015. Orchid phylogenomics and multiple drivers of their extraordinary diversification. Proc Royal Soc B: Biol Sci 282 (1814): 20151553. DOI: 10.1098/rspb.2015.1553

Hedrén M. 2001a. Systematics of the Dactylorhiza euxina/incarnatalmaculata polyploid complex (Orchidaceae) in Turkey: Evidence from allozyme data. Plant Syst Evol 229 (1): 23-44. DOI: $10.1007 / \mathrm{s} 006060170016$

Hedrén M. 2001b. Conservation priorities in Dactylorhiza, a taxonomically complex genus. Lindleyana 16 (1): 17-25

Hedrén M, Nordström S. 2009. Polymorphic populations of Dactylorhiza incarnata s.1. (Orchidaceae) on the Balticisland of Gotland: Morphology, habitat preference and genetic differentiation. Annals Bot 104 (3): 527-542. DOI: 10.1093/aob/mcp102

Heslop-Harrison J. 1951. A comparison of some Swedish and British forms of Orchis maculata L. sens. lat. Svensk Bot Tidskr 45: 608635.

Inda LA, Pimentel M, Chase MW. 2010. Chalcone synthase variation and phylogenetic relationships in Dactylorhiza (Orchidaceae). Bot J Linn Soc 163 (2): 155-165. DOI: 10.1111/j.1095-8339.2010.01055.x

IUCN. 2020. The IUCN Red List of Threatened Species. (http://www.iucnredlist.org).

Kaki A, Vafaee Y, Khadivi A. 2020. Genetic variation of Anacamptis coriophora, Dactylorhiza umbrosa, Himantoglossum affine, Orchis mascula, and Ophrys schulzei in the western parts of Iran. Industr Crops Prod 156: 112854. DOI: 10.1016/j.indcrop.2020.112854 
Kirillova IA, Kirillov DV, Shadrin DM. 2018. Morphological and molecular genetic approaches to the study of the genus Dactylorhiza in the Komi Republic. Bulletin of Tomsk State University (43): 4465. DOI: 10.17223/19988591/43/3. [Russian]

Landolt E. 1977. Okologische Zeigerwerte zur Schweizer Flora. Veroff. Geobot. Inst. Rubel. H.64. Stiftung Riibel, Zurich.

Naczk AM, Kowalkowska AK, Wiśniewska N, Haliński ŁP, Kapusta M, Czerwicka M. 2018. Floral anatomy, ultrastructure and chemical analysis in Dactylorhiza incarnata/maculata complex (Orchidaceae) Bot J Linn Soc 187 (3): 512-536. DOI: 10.1093/botlinnean/boy027

Pedersen HA. 2002. Dactylorhiza majalis s.1. (Orchidaceae) in acid habitats: Variation patterns, taxonomy, and evolution. Nordic J Bot 22 (6): 641-658. DOI: 10.1111/j.1756-1051.2002.tb01921.x

Pillon Y, Fay MF, Hedrén M, Bateman RM, Devey DS, Shipunov AB, van der Bank M, Chase MW. 2007. Evolution and temporal diversification of western European polyploid species complexes in Dactylorhiza (Orchidaceae). Taxon 56 (4): 1185-1208. DOI: 10.2307/25065911

Pillon Y, Fay MF, Shipunov AB, Chase MW. 2006. Species diversity versus phylogenetic diversity: A practical study in the taxonomically difficult genus Dactylorhiza (Orchidaceae). Biol Conserv 129 (1): 4 13. DOI: $10.1016 /$ j.birocon.2005.06.036

Red Book of Kazakhstan. 2014. Red Book of Kazakhstan. $2^{\text {nd }}$ ed., revised and enlarged. Volume 2: Plants. LLP "ArtPrint, Astana. [Russian]

Renz J, Taubenheim G. 1984. Dactylorhiza Necker ex Nevski. In: Davis PH (ed). Flora of Turkey and the East Aegean Islands. Edinburgh University Press, Edinburgh.

Shipunov A, Efimov P. 2015. "Northern tetraploids" clarified: A study of dactylorchids (Dactylorhiza, Orchidaceae) from North European Russia. Flora-Morphology, Distribution, Functional Ecology Plants 215: 40-45. DOI: 10.1016/j.flora.2015.07.005

Shipunov AB, Bateman RM. 2005b. Geometric morphometrics as a tool for understanding Dactylorhiza (Orchidaceae) diversity in European
Russia. Biol J the Linnean Soc 85 (1): 1-12. DOI: 10.1111/j.10958312.2005.00468.x

Shipunov AB, Fay MF, Chase MW. 2005a. Evolution of Dactylorhiza baltica (Orchidaceae) in European Russia: Evidence from molecular markers and morphology. Bot J the Linnean Soc 147 (3): 257-274. DOI: $10.1111 / \mathrm{j} .1095-8339.2005 .00380 . \mathrm{x}$

Shipunov AB, Fay MF, Pillon Y, Bateman RM, Chase MW. 2004. Dactylorhiza (Orchidaceae) in European Russia: Combined molecular and morphological analysis. Am J Bot 91: 1419-1426. DOI: 10.3732/ajb.91.9.1419

Shirokov AI, Syrova VV, Salokhin AV, Markelov IN, Andronova EV, Ganyushkina EV. 2020. Conservation issues and infraspecific polymorphism of Cypripedium guttatum on selected locations in Russia. Nat Conserv Res 5 (S1): 145-154. DOI: 10.24189/ncr.2020.054

Ståhlberg D, Hedrén M. 2008. Systematics and phylogeography of the Dactylorhiza maculata complex (Orchidaceae) in Scandinavia: Insights from cytological, morphological and molecular data. Plant Syst Evol 273 (1): 107-132. DOI: 10.1007/s00606-008-0035-x

Sumbembayev AA, Danilova AN, Abugalieva SI. 2020. List of Orchidaceae family of the Kazakhstan part of the Altai Mountains. Exp Biol 82 (1): 87-94. DOI: 10.26577/eb.2020.v82.i1.07

Tyteca D, Gathoye JL. 1999. Morphometric analysis of Dactylorhiza occitanica and related populations from eastern France (Orchidaceae). Belgian J Bot 132 (2): 158-174.

Vakhrameeva MG, Varlygina TI, Tatarenko IV. 2014. Orchids of Russia (Biology, Ecology and Conservation). Moscow. [Russian]

van Straaten D, Peymen J, Schneiders A, Verheyen R. 1988. The morphological variation of a population of Dactylorhiza maculata (L.) Soó (s.l.) in a base-rich marsh (Het Buitengoor, Belgium). Bulletin van de Nationale Plantentuin van Belgie 477-501. DOI: $10.2307 / 3668300$ 
Table S1. Results of measurements of metric features

\begin{tabular}{|c|c|c|c|c|c|c|c|c|c|c|c|c|c|}
\hline Abbrev. & $\begin{array}{l}\text { Feature name } \\
\text { (values in } \mathbf{m m} \text { ) }\end{array}$ & & $\begin{array}{l}\text { D. fuchsii } \\
\text { Pop. } 1\end{array}$ & $\begin{array}{l}\text { D. fuchsii } \\
\text { Pop. } 2\end{array}$ & $\begin{array}{l}\text { D. fuchsii } \\
\text { Pop. } 3\end{array}$ & $\begin{array}{c}\text { D. salina } \\
\text { Pop. } 1\end{array}$ & $\begin{array}{c}\text { D. salina } \\
\text { Pop. } 2\end{array}$ & D. maculata & $\begin{array}{c}D . \\
\text { incarnata } \\
\text { Pop. } 1 \\
\end{array}$ & $\begin{array}{c}D . \\
\text { incarnata } \\
\text { Pop. } 2 \\
\end{array}$ & $\begin{array}{c}D . \\
\text { incarnata } \\
\text { Pop. } 3 \\
\end{array}$ & $\begin{array}{c}D . \\
\text { incarnata } \\
\text { Pop. } 4 \\
\end{array}$ & $\begin{array}{c}D . \\
\text { incarnata } \\
\text { Pop. } 5\end{array}$ \\
\hline \multirow[t]{4}{*}{ LL } & labellum, length & $(\mathrm{M} \pm \mathrm{m})$ & $7.130 \pm 0.414$ & $8.955 \pm 0.890$ & $6.725 \pm 0.305$ & $8.080 \pm 0.676$ & $7.540 \pm 0.209$ & $7.260 \pm 0.312$ & $6.510 \pm 0.604$ & $6.540 \pm 0.183$ & $7.055 \pm 0.425$ & $8.042 \pm 0.297$ & $7.335 \pm 0.212$ \\
\hline & & min-max & $6.0-9.0$ & $5.0-11.6$ & $6-8.6$ & $5.6-11.4$ & $6.8-8.2$ & $6.2-9.0$ & $4.7-8.8$ & $5.3-7.3$ & $5.5-8.5$ & $6.8-8.9$ & $6.5-7.9$ \\
\hline & & $\mathrm{C} \%$ & 12.42 & 21.28 & .70 & 17.91 & 5.92 & 9.21 & 19.85 & 6.00 & 12.88 & 7.70 & 6.20 \\
\hline & & $\mathrm{P} \%$ & 2.78 & 4.76 & 2.17 & 4.00 & 1.32 & 2.06 & 4.44 & 1.34 & 2.88 & 1.77 & 1.39 \\
\hline \multirow[t]{4}{*}{ WL } & labellum, width & $(\mathrm{M} \pm \mathrm{m})$ & $9.915 \pm 0.583$ & $8.565 \pm 0.682$ & $9.180 \pm 0.411$ & $6.805 \pm 0.539$ & $9.085 \pm 0.300$ & $8.955 \pm 0.403$ & $7.376 \pm 0.767$ & $6.210 \pm 0.344$ & $8.770 \pm 0.908$ & $9.473 \pm 0.302$ & $9.385 \pm 0.545$ \\
\hline & & $\min -\max$ & $7.5-12.0$ & $5.9-10.9$ & 7.4-10.4 & $4.6-8.9$ & $7.8-10.2$ & $7.1-10$ & $4.7-9.9$ & $4.9-76$ & $5.8-11.5$ & $8.4-10.6$ & 7.3-11.2 \\
\hline & & $\mathrm{C} \%$ & 12.60 & 17.03 & 9.56 & 16.95 & 7.07 & 9.63 & 22.25 & 11.87 & 22.14 & 6.66 & 12.42 \\
\hline & & $\mathrm{P} \%$ & 2.82 & 3.81 & 2.14 & 3.79 & 1.58 & 2.15 & 4.98 & 2.65 & 4.95 & 1.53 & 2.78 \\
\hline \multirow[t]{4}{*}{ WSE } & spur, entrance, & $(\mathrm{M} \pm \mathrm{m})$ & $2.720 \pm 0.137$ & $2.440 \pm 0.228$ & $2.545 \pm 0.125$ & $2.325 \pm 0.229$ & $2.705 \pm 0.138$ & $3.620 \pm 0.148$ & $2.985 \pm 0.320$ & $2.320 \pm 0.266$ & $2.975 \pm 0.281$ & $4.163 \pm 0.147$ & $3.440 \pm 0.220$ \\
\hline & width & $\min -\max$ & $2.2-3.1$ & $1.6-3$ & $2.1-3.0$ & 1.7 & 2.1 & $2.7-4$ & $1.7-4.4$ & $1.3-3.5$ & $2.3-4.9$ & $3.5-4.8$ & $2.4-4.5$ \\
\hline & & $\mathrm{C} \%$ & 10.77 & 19.96 & .55 & 21.07 & 10. & 8.7 & 22.91 & 24.57 & 20.30 & 7.35 & 13.68 \\
\hline & & $\mathrm{P} \%$ & 2.41 & 4.46 & 36 & 4.71 & 2.44 & 1.96 & 5.12 & 5.49 & 4.54 & 1.69 & 3.06 \\
\hline \multirow[t]{4}{*}{ LDS } & sepal, dorsal, & $(\mathrm{M} \pm \mathrm{m})$ & 5.355 & 6.727 & 1 & 8.16 & 6.815 & 311 & $5.855 \pm 0.345$ & $5.655 \pm 0.190$ & $5.625 \pm 0.283$ & $7.805 \pm 0.179$ & $6.620 \pm 0.297$ \\
\hline & lengtl & $\min -\max$ & $4.2-7.0$ & 2.0 & & 10 & & & $4.8-7.1$ & $4.8-6.2$ & $4.5-6.6$ & $7.0-8.5$ & $4.9-7.5$ \\
\hline & & $\mathrm{C} \%$ & 14.02 & 24.41 & 2.01 & 58 & 11.41 & 9.7 & 12.61 & 7.20 & 10.77 & 4.80 & 9.60 \\
\hline & & $\mathrm{P} \%$ & 3.13 & 5.46 & 2.68 & 2.14 & 2.55 & 2.19 & 2.82 & 1.61 & 2.41 & 1.10 & 2.15 \\
\hline \multirow[t]{4}{*}{ WDS } & Width & $(\mathrm{M} \pm \mathrm{m})$ & 58 & 2.3 & 78 & & 2. & & $2.765 \pm 0.201$ & $1.760 \pm 0.178$ & $2.415 \pm 0.223$ & $2.726 \pm 0.084$ & $2.485 \pm 0.143$ \\
\hline & dorsa & $\min -\max$ & & & & & & & & $0.9-2.4$ & $1.8-4.0$ & & \\
\hline & & $\mathrm{C} \%$ & 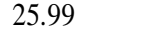 & & & & & & & 21.61 & 19.71 & 6.45 & 12.34 \\
\hline & & $\mathrm{P} \%$ & 5.81 & 2.85 & 4.26 & 3.57 & 2.92 & 3.39 & 3.48 & 4.83 & 4.41 & 1.48 & 2.76 \\
\hline \multirow[t]{4}{*}{ LLS } & sepals, & $(\mathrm{M} \pm \mathrm{m})$ & $6.435 \pm 0.453$ & 8.475 & 73 & 9.695 & \pm 0.272 & .337 & $6.510 \pm 0.568$ & $6.975 \pm 0.272$ & $7.380 \pm 0.359$ & $9.657 \pm 0.376$ & $8.075 \pm 0.380$ \\
\hline & lateral,length & $\min -\max$ & $4.2-8.0$ & $5.25-11.0$ & $1.7-7.3$ & $8.1-11.7$ & 9.0 & $7.2-10.0$ & $4.2-8.3$ & $5.8-8.0$ & $5.8-9.1$ & $8.5-12.1$ & $6.2-9.3$ \\
\hline & & $\mathrm{C} \%$ & 15.06 & 17.17 & 19.44 & 11.69 & 7.18 & 8.69 & 18.66 & 8.36 & 10.41 & 8.11 & 10.07 \\
\hline & & $\mathrm{P} \%$ & 3.37 & 3.84 & 4.35 & 2.61 & 1.60 & 1.94 & 4.17 & 1.87 & 2.33 & 1.86 & 2.25 \\
\hline \multirow{4}{*}{ WLS } & sepals, lateral, & $(\mathrm{M} \pm \mathrm{m})$ & $2.260 \pm 0.185$ & 0.220 & 0.159 & $3.105 \pm 0$ & $3.550 \pm 0.185$ & $3.775 \pm 0.125$ & $3.135 \pm 0.255$ & $2.325 \pm 0.248$ & $3.065 \pm 0.241$ & $3.800 \pm 0.159$ & $3.535 \pm 0.230$ \\
\hline & width & min-max & $1.6-$ & & & $2.3-4.5$ & $3.0-$ & $3.2-4.2$ & $2.2-4.0$ & $1.3-3.1$ & $2.3-4.4$ & $3.2-4.3$ & $1.9-4.0$ \\
\hline & & $\mathrm{C} \%$ & 17.55 & 19.36 & 7 & 16.40 & 1113 & 708 & 17.39 & 22.84 & 16.85 & 8.73 & 13.93 \\
\hline & & $\mathrm{P} \%$ & 3.92 & 4.33 & 3.39 & 3.67 & 2.49 & 1.5 & 3.89 & 5.11 & 3.77 & 2.00 & 3.11 \\
\hline \multirow[t]{4}{*}{ LS } & spur, length & $(\mathrm{M} \pm \mathrm{m})$ & $5.855 \pm 0.433$ & $5.250 \pm 0.353$ & $6.685 \pm 0.308$ & $9.805 \pm 0.899$ & $13.817 \pm 0.408$ & $8.380 \pm 0.413$ & $5.567 \pm 0.348$ & $6.365 \pm 0.264$ & $6.832 \pm 0.201$ & $5.321 \pm 0.329$ & $8.135 \pm 0.230$ \\
\hline & & $\min -\max$ & $4.2-8.0$ & $3.7-6.7$ & $5.6-7.8$ & $6.6-15.0$ & $12.7-15.9$ & $6.9-9.5$ & $4.2-6.7$ & $5.6-7.6$ & $6.05-7.6$ & $3.4-6.4$ & $6.6-9.1$ \\
\hline & & $\mathrm{C} \%$ & 15.83 & 14.38 & 9.85 & & 6.32 & 10.56 & 13.39 & 8.87 & 6.30 & 12.89 & 7.88 \\
\hline & & $\mathrm{P} \%$ & 3.54 & 3.22 & 2.20 & 4.39 & 1.14 & 2.36 & 2.99 & 1.98 & 1.41 & 2.96 & 1.76 \\
\hline \multirow[t]{4}{*}{ WS } & spur (mid), width & $(\mathrm{M} \pm \mathrm{m})$ & $1.735 \pm 0.536$ & $1.550 \pm 0.138$ & $1.580 \pm 0.109$ & $1.795 \pm 0.165$ & $2.610 \pm 0.215$ & $2.895 \pm 0.116$ & $2.249 \pm 0.191$ & $1.505 \pm 0.177$ & $2.115 \pm 0.218$ & $2.831 \pm 0.194$ & $3.040 \pm 0.248$ \\
\hline & & $\min -n$ & $1.0-6.5$ & $1.0-2.0$ & & & & & $1.60-2.99$ & $0.8-2.4$ & $1.3-2.9$ & $2.2-3.9$ & $2.1-4.2$ \\
\hline & & $\mathrm{C} \%$ & & & & & & & 18.17 & 25.18 & 22.03 & 14.32 & 17.45 \\
\hline & & $\mathrm{P} \%$ & 14.79 & 4.26 & 3.33 & 4.40 & 3.94 & 1.92 & 4.06 & 5.63 & 4.93 & 3.29 & 3.90 \\
\hline
\end{tabular}




\begin{tabular}{|c|c|c|c|c|c|c|c|c|c|c|c|c|c|}
\hline & & & & & & & & & & & & & \\
\hline$\overline{\text { LLL }}$ & labellum, lateral & $(\mathrm{M} \pm \mathrm{m})$ & $6.010 \pm 0.331$ & $5.567 \pm 0.618$ & $5.175 \pm 0.258$ & $7.050 \pm 0.585$ & $6.905 \pm 0.256$ & $5.655 \pm 0.250$ & $5.380 \pm 0.640$ & $4.780 \pm 0.250$ & $5.335 \pm 0.459$ & $6.163 \pm 0.238$ & $5.750 \pm 0.312$ \\
\hline & lobe, length & $\min -\max$ & $5.0-7.5$ & $1.9-7.0$ & $4.3-6.3$ & $4.5-9.3$ & $6.0-8.1$ & $4.3-6.8$ & $3.5-7.8$ & $3.8-6.0$ & $3.8-6.7$ & $5.1-6.9$ & $4.6-7.0$ \\
\hline & & $\mathrm{C} \%$ & 11.8 & 23.75 & 10.66 & 17.76 & 7.94 & 9.47 & 25.49 & 11.19 & 18.43 & 8.04 & 11.60 \\
\hline & & $\mathrm{P} \%$ & 2.64 & 5.31 & 2.38 & 3.97 & 1.78 & 2.12 & 5.70 & 2.50 & 4.12 & 1.85 & 2.59 \\
\hline WLL & labellum, lateral & $(\mathrm{M} \pm \mathrm{m})$ & $3.715 \pm 0.303$ & $3.145 \pm 0.324$ & $3.535 \pm 0.243$ & $2.557 \pm 0.299$ & $3.680 \pm 0.223$ & $3.228 \pm 0.207$ & $2.565 \pm 0.405$ & $2.082 \pm 0.157$ & $2.975 \pm 0.401$ & $3.547 \pm 0.203$ & $3.495 \pm 0.327$ \\
\hline & lobe, width & $\min -\max$ & $2.5-4.9$ & $2.0-4.4$ & $2.7-4.8$ & $1.7-4.1$ & $3.0-5.0$ & $2.6-4.0$ & $1.3-4.2$ & $1.6-3.0$ & $1.7-4.3$ & $2.6-4.3$ & $2.2-5.1$ \\
\hline & & $\mathrm{C} \%$ & 17.45 & 22.01 & 14.69 & 25.03 & 12.95 & 13.69 & 33.79 & 16.18 & 28.83 & 11.94 & 20.03 \\
\hline & & $\mathrm{P} \%$ & 3.90 & 4.92 & 3.29 & 5.60 & 2.89 & 3.06 & 7.55 & 3.62 & 6.45 & 2.74 & 4.48 \\
\hline LBS & labellum, from & $(\mathrm{M} \pm \mathrm{m})$ & $4.615 \pm 0.312$ & $4.027 \pm 0.376$ & $3.595 \pm 0.261$ & $6.830 \pm 0.570$ & $6.865 \pm 0.255$ & $5.370 \pm 0.188$ & $5.170 \pm 0.634$ & $4.605 \pm 0.321$ & $4.860 \pm 0.333$ & $5.763 \pm 0.302$ & $5.320 \pm 0.225$ \\
\hline & base of entrance to & $\min -\max$ & $3.0-6.0$ & $3.0-5.5$ & $1.8-4.7$ & $4.3-9.0$ & $6.0-8.1$ & $4.6-6.1$ & $3.5-7.4$ & $3.5-6.0$ & $3.8-5.9$ & $4.1-6.5$ & $4.4-6.3$ \\
\hline & base of sinus, & $\mathrm{C} \%$ & 14.45 & 19.96 & 15.54 & 17.86 & 7.94 & 7.50 & 26.25 & 14.90 & 14.66 & 10.92 & 9.04 \\
\hline & length & $\mathrm{P} \%$ & 3.23 & 4.46 & 3.34 & 3.99 & 1.78 & 1.68 & 5.87 & 3.33 & 3.28 & 2.50 & 2.02 \\
\hline LO & ovary, length & $(\mathrm{M} \pm \mathrm{m})$ & $9.470 \pm 0.797$ & $10.402 \pm 0.885$ & $10.825 \pm 0.664$ & $12.835 \pm 0.870$ & $16.585 \pm 0.598$ & $14.095 \pm 0.528$ & $10.780 \pm 1.14$ & $10.660 \pm 0.54$ & $12.905 \pm 0.71$ & $14.884 \pm 0.87$ & $13.825 \pm 0.64$ \\
\hline & & $\min -\max$ & $6.5-12.5$ & 7.0-13.4 & $8.2-13$ & $9.5-16.0$ & $14.2-$ & $12.6-17.0$ & 3 & 5 & 1 & 2 & 9 \\
\hline & & $\mathrm{C} \%$ & 18.01 & 18.20 & 13.13 & 14.50 & 7.72 & 8.02 & $8.3-16.5$ & $8.5-13.0$ & $10.0-16.5$ & $11.3-17.8$ & $11.7-17.0$ \\
\hline & & $\mathrm{P} \%$ & 4.03 & 4.07 & 2.94 & 3.24 & 1.73 & 1.79 & 22.70 & 10.95 & 11.79 & 12.22 & 10.05 \\
\hline & & & & & & & & & 5.0 & 2.45 & 2.64 & 2.80 & 2.25 \\
\hline$[\mathrm{LML}=\mathrm{L}$ & labellu & $(\mathrm{M} \pm \mathrm{m})$ & $2.515 \pm 0.283$ & $4.927 \pm 0.723$ & $3.130 \pm 0.319$ & $=0.300$ & $=0.197$ & $1.890 \pm 0.272$ & \pm 0.176 & $1.935 \pm 0.339$ & $2.195 \pm 0.213$ & $2.278 \pm 0.204$ & $2.015 \pm 0.187$ \\
\hline L-LBS] & lobe, length & $\min -\max$ & $1.5-3.5$ & $2.0-8.5$ & $2.3-5.1$ & $0.4-2.5$ & $0.1-1.9$ & $0.9-3.5$ & $0.7-2.3$ & $0.5-3.0$ & $1.6-3.0$ & $1.7-3.3$ & $1.3-2.7$ \\
\hline & & $\mathrm{C} \%$ & 24.04 & 31.38 & 21.82 & 51.42 & 62.46 & 30.85 & 28.07 & 37.50 & 20.77 & 18.71 & 19.87 \\
\hline & & $\mathrm{P} \%$ & 5.38 & 7.02 & 4.88 & 11.5 & 13.97 & 6.90 & 6.28 & 8.39 & 4.64 & 4.29 & 4.44 \\
\hline WML & labellum, middle & $(\mathrm{M} \pm \mathrm{m})$ & $2.980 \pm 0.207$ & $2.065 \pm 0.064$ & $2.235 \pm 0.126$ & $2.205 \pm 0.305$ & $2.340 \pm 0.267$ & $2.825 \pm 0.223$ & $2.664 \pm 0.169$ & $1.905 \pm 0.248$ & $2.875 \pm 0.198$ & $3.205 \pm 0.193$ & $3.075 \pm 0.272$ \\
\hline & lobe, width & $\min -\max$ & $2.0-3.7$ & $1.75-2.30$ & $1.6-2.5$ & $1.2-3.5$ & $1.5-3.5$ & $1.8-3.5$ & $2.0-3.2$ & $0.9-3.0$ & $2.0-3.5$ & $2.7-4.1$ & $2.2-4.1$ \\
\hline & & $\mathrm{C} \%$ & 14.87 & 6.72 & 12.08 & 2956 & 24.43 & 16.87 & 13.57 & 27.91 & 14.71 & 12.59 & 18.90 \\
\hline & & $\mathrm{P} \%$ & 3.33 & 1.50 & 2.70 & 6.61 & 5.46 & 3.77 & 3.04 & 6.24 & 3.29 & 2.89 & 4.23 \\
\hline LP & petals, length & $(\mathrm{M} \pm \mathrm{m})$ & $5.860 \pm 0.217$ & $7.182 \pm 0.530$ & $6.115 \pm 0.291$ & $8.900 \pm 0.379$ & $7.265 \pm 0.354$ & $7.290 \pm 0.203$ & $6.360 \pm 0.659$ & $6.250 \pm 0.296$ & $6.085 \pm 0.394$ & $8.405 \pm 0.263$ & $7.260 \pm 0.292$ \\
\hline & & $\min -\max$ & $5.0-6.7$ & $4.25-8.90$ & $5.2-7.5$ & $7.7-10.5$ & $5.9-8.5$ & $6.2-7.9$ & $2.6-8.7$ & $4.7-7.2$ & $4.6-8.0$ & 7.4-9.5 & $6.0-8.2$ \\
\hline & & $\mathrm{C} \%$ & 7.92 & 15.81 & 10.20 & 9.12 & 10.44 & 5.95 & 22.16 & 10.14 & 13.85 & 6.52 & 8.60 \\
\hline & & $\mathrm{P} \%$ & 1.77 & 3.54 & 2.28 & 2.04 & 2.33 & 1.33 & 4.95 & 2.27 & 3.09 & 1.50 & 1.92 \\
\hline WP & petals, width & $(\mathrm{M} \pm \mathrm{m})$ & $2.510 \pm 0.159$ & $2.687 \pm 0.207$ & $2.355 \pm 0.128$ & $2.805 \pm 0.268$ & $3.390 \pm 0.206$ & $3.220 \pm 0.169$ & $2.877 \pm 0.186$ & $2.067 \pm 0.188$ & $2.800 \pm 0.250$ & $3.857 \pm 0.138$ & $3.190 \pm 0.163$ \\
\hline & & $\min -\max$ & $1.6-3.0$ & $1.6-3.4$ & $1.9-2.7$ & $1.6-3.9$ & $2.7-4.2$ & $2.6-4.2$ & $2.1-3.6$ & $1.3-2.8$ & $1.9-3.8$ & $3.2-4.3$ & $2.3-3.6$ \\
\hline & & $\mathrm{C} \%$ & 13.55 & 16.51 & 11.65 & 20.45 & 13.01 & 11.25 & 13.86 & 19.41 & 19.11 & 7.45 & 10.95 \\
\hline & & $\mathrm{P} \%$ & 3.03 & 369 & 2.60 & 4.57 & 2.91 & 2.15 & 3.09 & 4.34 & 4.27 & 1.71 & 2.45 \\
\hline$=\frac{2 * L L}{L B S+L L L}$ & $\begin{array}{l}\text { Labellum shape } \\
\text { index }\end{array}$ & & 1.4 & 1.8 & 1.5 & 1.2 & 1.1 & 1.3 & 1.2 & 1.4 & 1.4 & 1.3 & 1.3 \\
\hline
\end{tabular}

Note: $\mathrm{M}$ - average value of the metric feature, $\mathrm{m}$ - allowable limits, min-max - minimum and maximum feature values, C\% - coefficient of variation of a feature, P\% - relative error of the sample mean (accuracy of the experiment) 